\title{
Acute Effects of Whole-Body Vibration on Lower Body Flexibility and Strength
}

Patricia A. Burns ${ }^{1}$; Kristina S. Beekhuizen ${ }^{1,2}$; Patrick L. Jacobs, FACSM ${ }^{1,2}$.

1) University of Miami School of Medicine, Miami FL. 2) Miami VA Medical Ctr, Miami, FL.

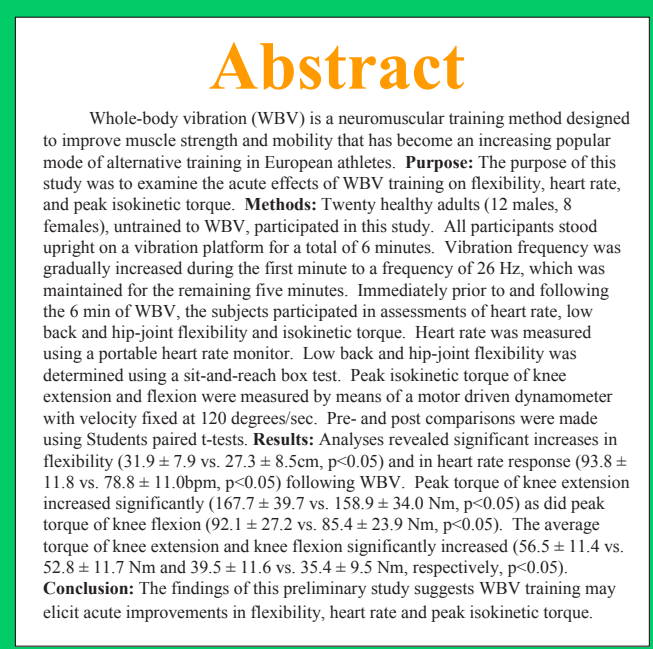

\section{Introduction}

Whole-body vibration (WBV) is a neuromuscular training method designed to increase muscular strength and mobility that has been a popular mode of alternative training in European athletes. WBV has
also recently been examined in various research fields, including sports and exercise sciences (1-6), chronic pain management (7), and musclar power and vertical jump in healthy adults (1-6) Addition research indicates WBV may alleviate chronic lower back pain (7) and increase balance and muscular power in geriatric patients (8). Whole-body vibration is thought to elicit muscular activity via stretch reflexes (3,4). The Galileo'm 2000 (White Plains, NY.) was developed to mechanically stimulate muscles at specific frequencies, typically $25-30 \mathrm{~Hz}$, causing the nimscles to contract and relax by natu directional, oscillating pette beed on the concept of a center a oneand an alternating up/down motionPresently, the extent of clinical research into the acute effects of WBV is limited. Thus, the purpose of this investigation was to examine the acute response of WBV on lower body flexibility and muscular strength

\section{Methods}

Wenty healthy persons ( 12 males, 8 females) (age $28.8 \pm 8.9 \mathrm{yr}$; body mass $76.9 \pm 20.2 \mathrm{~kg}$; height $174.6 \pm 9.6 \mathrm{~cm}$ ) voluthteered to participate in this study. Each participant stood upright on the

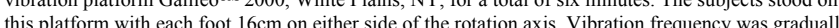

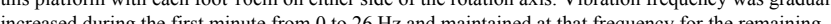
five minutes. The WVB training was performed with the subjects standing with their whole foot on the vibration platform with minimal bend in the knees. All subjects wore rubber soled athletic shoes during the $\mathrm{WBV}$ training

Immediately prior to, and following, the six minutes of WBV training, the subjects participated in heart rate assessment, a Sit-and-Reach Box test and isokinetic evaluations of knee extension and flexion. Heart rate was conthuously monttored using a Polar 61 in Heart Rate Monitor (Polar Electro Oy, Finland). The Sit perf(9). Isokinetic torque was measured by means of a motor driven isokinetic dynamometer Biode System 2, (Shirley, NY.), with velocity fixed at 120 degrees/second. Subjects performed one set of five concentric flexion/extension movements. Peak and average torque were determined in the repetition having the greatest peak torque. The knee extension movement was initiated at a joint angle of 90 degrees and terminated at 160 degrees.

Pences. Significance level was set at $\mathrm{P}<0.05$.
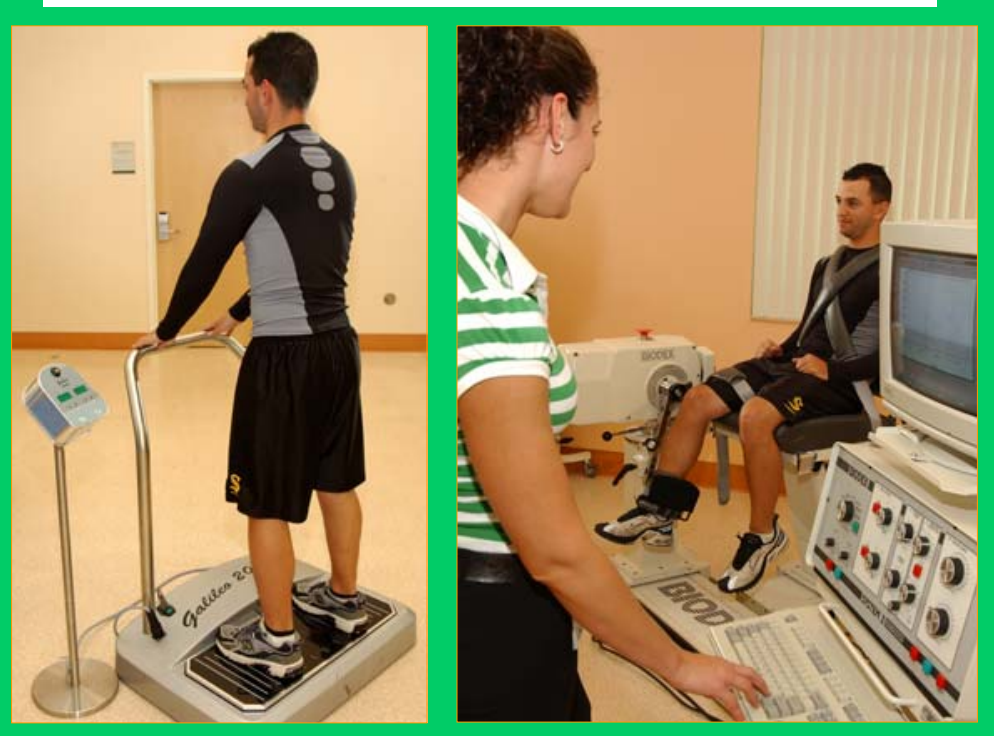

\section{Results}

Results indicated that WBV training produced significant increases in heart rate response, flexibility, and peak and average torque $(\mathfrak{p}<0.05)$

HR (beats $\left.\cdot \min ^{-1}\right)$

FLEXIBILITY $(\mathrm{cm})$

PEAK TORQUE (Extension) $(\mathrm{Nm}) \quad 158.9 \pm 34.0$

PEAK TORQUE (Flexion) (Nm) $\quad 85.4 \pm 23.9$

AVERAGE TORQUE (Extension) (Nm) $\quad 52.8 \pm 11.7$

POST

$93.8 \pm 11.8 *$

$31.9 \pm 7.9 *$

$167.7 \pm 39.7 *$

$92.1 \pm 27.2 *$

$56.5 \pm 11.4 *$

* denotes values are statistically significant $\mathrm{P}<0.05$

$39.5 \pm 11.6 *$

\section{Conclusion}

The findings of this preliminary study suggest WBV training may elicit acute increases in heart rate response, low back and hip-joint flexibility and peak isokinetic torque. It is evident that more research on WBV is needed to explain the physiological and neurological mechanisms of muscle strength and/or power gain examine how the acute effects to WBV compare with those to other modes of war up and to various exercise training modalities.

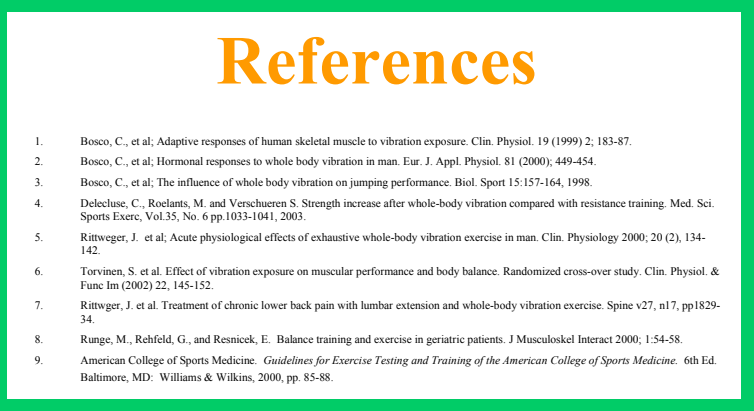

